\title{
UNEP-SETAC guideline on global land use impact assessment on biodiversity and ecosystem services in LCA
}

\author{
Thomas Koellner • Laura de Baan • Tabea Beck • \\ Miguel Brandão • Barbara Civit • Manuele Margni • \\ Llorenç Milà i Canals • Rosie Saad • \\ Danielle Maia de Souza $\cdot$ Ruedi Müller-Wenk
}

Received: 14 June 2011 / Accepted: 2 April 2013 /Published online: 1 May 2013

(C) The Author(s) 2013. This article is published with open access at Springerlink.com

\begin{abstract}
Purpose As a consequence of the multi-functionality of land, the impact assessment of land use in Life Cycle Impact Assessment requires the modelling of several impact pathways covering biodiversity and ecosystem services. To provide consistency amongst these separate impact pathways, general principles for their modelling are provided in this paper. These are refinements to the principles that have already been proposed in publications by the UNEP-SETAC Life Cycle Initiative. In particular, this paper addresses the calculation of land use interventions and land use impacts, the issue of impact reversibility, the spatial and
\end{abstract}

Responsible editor: Roland Geyer

Electronic supplementary material The online version of this article (doi:10.1007/s11367-013-0579-z) contains supplementary material, which is available to authorized users.

T. Koellner $(\bowtie) \cdot$ D. M. de Souza

Faculty of Biology, Chemistry and Geosciences,

University of Bayreuth, GEO II,

Room 1.17, Universitaetsstr. 30,

95440 Bayreuth, Germany

e-mail: thomas.koellner@uni-bayreuth.de

\section{L. de Baan}

Natural and Social Science Interface, Institute for Environmental Decisions, ETH Zurich, Universitaetstr. 22,

8092 Zurich, Switzerland

T. Beck

Department Life Cycle Engineering, University of Stuttgart,

Hauptstrasse 113,

70771 Leinfelden-Echterdingen, Germany

\section{Brandão $\cdot$ D. M. de Souza}

Institute for Environment and Sustainability, Sustainability

Assessment Unit, European Commission, Joint Research Centre,

Via Enrico Fermi 2749

21027 Ispra, Varese, Italy temporal distribution of such impacts and the assessment of absolute or relative ecosystem quality changes. Based on this, we propose a guideline to build methods for land use impact assessment in Life Cycle Assessment (LCA).

Results Recommendations are given for the development of new characterization models and for which a series of key elements should explicitly be stated, such as the modelled land use impact pathways, the land use/cover typology covered, the level of biogeographical differentiation used for the characterization factors, the reference land use situation used and if relative or absolute quality changes are used to calculate land
B. Civit

Facultad Regional Mendoza/CONICET, Universidad Tecnológica Nacional, Rodríguez 273,

5500 Mendoza, Argentina

M. Margni $\cdot$ R. Saad

Département de génie chimique,

CIRAIG, École Polytechnique de Montréal,

6079 Montréal, Canada

L. M. i Canals

Safety and Environmental Assurance Centre, Unilever R\&D

Colworth Park, Sharnbrook, Bedford MK44 1LQ, UK

R. Müller-Wenk

Institute for Economy and the Environment, University of

St. Gallen, Tigerbergstrasse 2,

9000 St.Gallen, Switzerland 
use impacts. Moreover, for an application of the characterisation factors (CFs) in an LCA study, data collection should be transparent with respect to the data input required from the land use inventory and the regeneration times. Indications on how generic CFs can be used for the background system as well as how spatial-based CFs can be calculated for the foreground system in a specific LCA study and how land use change is to be allocated should be detailed. Finally, it becomes necessary to justify the modelling period for which land use impacts of land transformation and occupation are calculated and how uncertainty is accounted for.

Discussion The presented guideline is based on a number of assumptions: Discrete land use types are sufficient for an assessment of land use impacts; ecosystem quality remains constant over time of occupation; time and area of occupation are substitutable; transformation time is negligible; regeneration is linear and independent from land use history and landscape configuration; biodiversity and multiple ecosystem services are independent; the ecological impact is linearly increasing with the intervention; and there is no interaction between land use and other drivers such as climate change. These assumptions might influence the results of land use Life Cycle Impact Assessment and need to be critically reflected. Conclusions and recommendations In this and the other papers of the special issue, we presented the principles and recommendations for the calculation of land use impacts on biodiversity and ecosystem services on a global scale. In the framework of LCA, they are mainly used for the assessment of land use impacts in the background system. The main areas for further development are the link to regional ecological models running in the foreground system, relative weighting of the ecosystem services midpoints and indirect land use.

Keywords Biodiversity $\cdot$ Ecological functions $\cdot$ Ecosystem services $\cdot$ Life cycle assessment $\cdot$ Land use

\section{Introduction}

Life Cycle Assessment (LCA) is a tool to support decisionmaking widely used to assess the potential environmental impacts of a given product/service at each step of its life cycle. Impacts at the global and regional scales are accounted for, such as climate change, eutrophication, acidification, toxicological effects and abiotic resource use. Early attempts to integrate direct and indirect land use in LCA (Lindeijer et al. 2002; Milà i Canals 2007a; Reinhard and Zah 2009) and its impact on biodiversity (e.g. Koellner and Scholz 2007; Koellner and Scholz 2008; Michelsen 2008; Schmidt 2008; Geyer et al. 2010a) and on ecological functions (e.g. Lindeijer et al. 2002; Milà i Canals L 2003; Milà i Canals L 2003; Milà i Canals 2007a; Beck et al. 2010; Saad et al. 2011) have been made, but these are still not fully operational or widely applied.
Although functional species diversity is an important factor in the cause-effect chain from land use to ecosystem functioning and services (Balvanera et al. 2006; Flynn et al. 2009), functional aspects of biodiversity are not yet considered (see the review from Curran et al. 2011). Moreover, only preliminary studies explicitly discuss ecosystem services in LCA (Maes et al. 2009; Zhang et al. 2010a, b; Bare 2011) and this concept generally refers to life support functions (de Groot 1992; de Groot et al. 2002) introduced early into LCA (e.g. Udo de Haes et al. 2002; Antón et al. 2007; Milà i Canals 2007b).

The problem with all those attempts to integrate land use impacts on biodiversity, ecological functions and ecosystem services into LCA is their limited focus on one geographical scope such as case study regions of some square kilometres or larger specific biogeographical regions like Canada or Central Europe. However, the strength of LCA is to provide a life cycle perspective (Milà i Canals et al. 2007) and thus requires methods that are able to account for an assessment of land use impacts related to a variety of land use types and locations. Even simple products like milk imply globally distributed land use through e.g. the supply chain of the concentrate feed (Cederberg and Mattsson 2000). Also the increasing demand for studies on biofuels and their environmental footprint shows that a globally applicable Life Cycle Impact Assessment (LCIA) method is needed to assess land use impacts on biodiversity and ecosystem services.

In summary, land use impact assessment in LCA has moved significantly since the early works of SETAC (Lindeijer et al. 2002) and the first phase of the UNEPSETAC Life Cycle Initiative (Milà i Canals et al. Milà i Canals 2007a), with increasing attempts to integrate land use impacts in LCA. Now, more consistency is needed in order to take stock of what has been suggested to date and provide alignment in the future modelling of different impact pathways.

This paper builds on the "Key Elements in a Framework for Land Use Impact Assessment Within LCA" that was developed in the context of the UNEP-SETAC Life Cycle Initiative (Milà i Canals 2007a). The aim of the current paper is to move beyond the description of key elements by suggesting specific guidelines for a comprehensive and consistent impact assessment encompassing all pathways that originate from land use and damages on biodiversity and ecosystem services. Such guidelines are applied and exemplified throughout this special issue, first by developing a globally consistent Life Cycle Inventory (LCI) classification system (Koellner et al. 2013) then, by proposing new methods for the different impact pathways affecting biodiversity (de Baan et al. 2013; Souza et al. 2013) and ecosystem services (Müller-Wenk and Brandão 2010; Beck et al. 2010; Brandão and Milà i Canals L 2013; Saad et al. 2013) and finally, by illustrating the previous new methods and recommendations in a case study on margarine production (Milà i Canals L et al. 2013). 


\section{Principles of a globally applicable land use impact assessment method}

2.1 Land use interventions and their impacts on ecosystem quality

Two types of land use interventions are usually considered in life cycle inventories and impact assessments; land transformation and land occupation (Lindeijer et al. 2002; Milà i Canals 2007b). During land transformation (also called land use change, LUC), the properties of a piece of land are modified to make it suitable for an intended use such as deforesting or draining land to establish arable fields. The phase of transformation is relatively short, and the temporal dimension is neglected. During land occupation, land is used in the intended productive way (e.g. arable field) and the properties of a piece of land are maintained (e.g. the regrowth of forest is avoided on an arable field).

These land use interventions have an impact on ecosystem quality $Q$ over a certain period of time, where $Q$ can be defined as the capability of an ecosystem (or a mix of ecosystems at the landscape scale) to sustain biodiversity and to deliver services to the human society. This refers to the area of protection natural environment, which provides the "intrinsic value of nature (ecosystems, species) and the economic value of life support functions" to the human society (Udo de Haes et al. 1999a, b). Land use impacts and damages to ecosystem quality may be measured with different indicators expressing the intrinsic value of biodiversity and natural landscapes or the functional value of ecosystems in terms of their goods (i.e. natural resources like timber or food) and services (i.e. life support functions like climate regulation or erosion regulation) (sensu Milà $i$ Canals 2007a). These impacts result from both land occupation (because ecosystem quality is kept at a different level than would naturally/otherwise be present) and land transformation (because the characteristics of ecosystems are changed on purpose).
If no occupation process would follow a land transformation, the forces of nature would gradually change the ecosystem quality towards its initial quality (although the original ecosystem quality might not be reached, see Section 2.2). The impact of land transformation (TI) is calculated as the integral of the difference in ecosystem quality between the land use situation and a suitable reference $(\Delta Q)$ over time, multiplied by the transformed area $(A)$. As the temporal dynamics of ecosystem quality are mostly unknown, a linear trajectory of ecosystem regeneration is assumed (Fig. 1). Transformation impacts are then calculated using Eq. (1), whereby $t_{\text {reg }}$ is the time required for full regeneration of ecosystem quality.

$T I=0.5 \times \Delta Q \times t_{\text {reg }} \times A$

The inventory flow records the area $A$ transformed and the characterization factor of transformation $C F_{\text {trans }}$ is given in Eq. (2):

$C F_{\text {trans }}=0.5 \times \Delta Q \times t_{\text {reg }}$

Accordingly, the impact of land occupation $(O I)$ is calculated as the integral of $\Delta Q$ over time multiplied by the occupied area $A$ (Eq. (3)). By assuming that $\Delta Q$ is constant during the occupation phase, occupation impacts are calculated following Eq. (3) (with $T$ being the time that a piece of land is occupied).

$O I=\Delta Q \times T \times A$

Here, the inventory flow is given as $A_{\mathrm{occ}} \times T_{\mathrm{occ}}$ and the characterization factor of occupation $C F_{o c c}$ is given in Eq. (4):

$C F_{\text {occ }}=\Delta Q$

Figure 1 illustrates three examples of typical land use interventions and their associated impacts on ecosystem quality. For simplicity, the area $A$ of occupation or transformation, which would embrace the third dimension, is not
Fig. 1 Simplified illustration of transformation impact $(T I)$ and occupation impact $(O I)$ for three land use types with different regeneration rates $\left(t_{L U 1, \text { reg, }} t_{L U 2, \text { reg }}\right.$ and $\left.t_{L U 3, \text { reg }}\right)$. For simplicity, the area $A$ of occupation or transformation, which would embrace the third dimension, is not shown in the graph, but in the equations

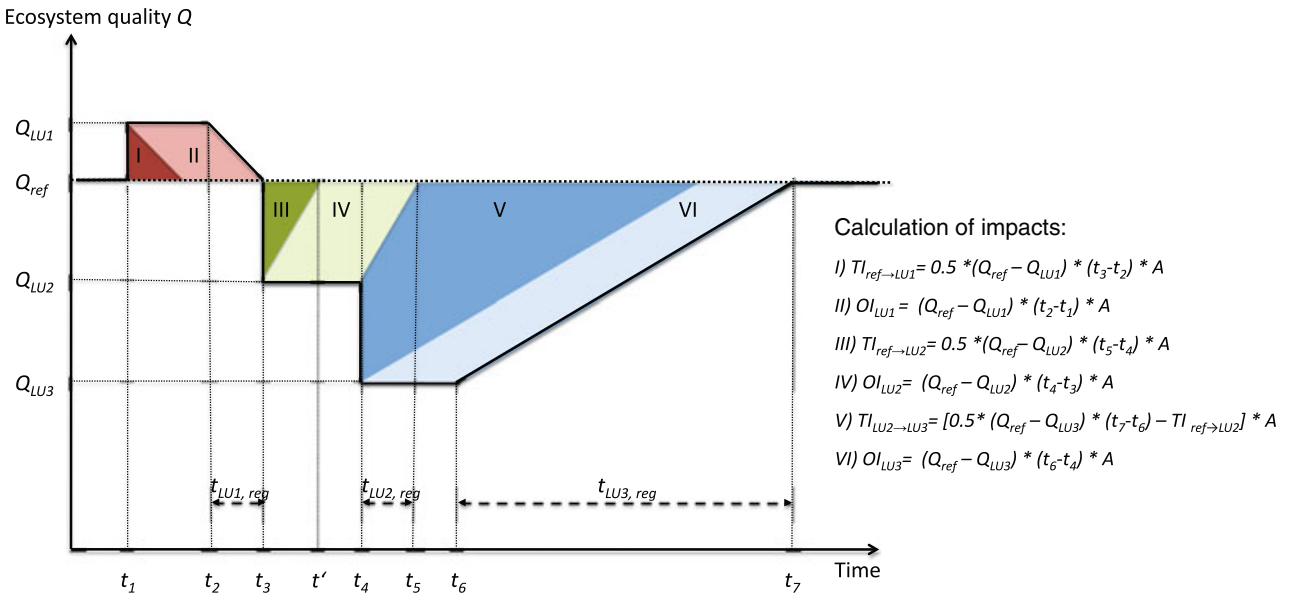


shown and the measured impact indicator discussed refers to impacts on biodiversity. However, the same reasoning applies for other land use impact pathways. First, at time $t_{1}$, the land is transformed from a reference (e.g. broadleaf lowland forest) to land use type $L U 1$ (e.g. species-rich dry meadow), indicating a higher ecosystem quality (if measured as biodiversity) than the reference. The transformation impact is given as the difference in ecosystem quality $\left(Q_{r e f}-Q_{L U I}\right)$ multiplied by the time it would take after abandoning $L U 1$ to restore the reference (e.g. the time required for a lowland broadleaf forest to naturally establish on a dry meadow). Both the transformation (area I in Fig. 1) and occupation impact (II) result in negative values, which denote a benefit for ecosystem quality. In the second situation, at time $t_{3}$, land is transformed from a reference (e.g. broadleaf lowland forest) to land use type $L U 2$ (e.g. intensive pasture). Here, the land transformation (III) and occupation (IV) show damaging impacts on ecosystem quality (i.e. positive values for $T I$ and $O I$ ). In the third situation (time $t_{4}$ ), land is transformed from $L U 2$ (e.g. intensive pasture) to $L U 3$ (e.g. intensive arable crops). The occupation impact (VI) is calculated as in the two previous examples. The transformation impact (area V) can be calculated by subtracting the impact of transforming a land from the reference to $L U 2\left(T I_{r e f-}>L U 2\right)$ from the impacts of transforming land from the reference to LU3 (TI ref $>L U 3$; see Eq. V in Fig. 1). Also, it is important to note that the regeneration times of ecosystems are dependent on the land use type $\left(t_{L U 1, \text { reg }} \neq t_{L U 1, \text { reg }} \neq t_{L U 1, \text { reg }}\right)$. Details on the separation of transformation into two separate flows "transformation from" and "transformation to" are given in the Electronic Supplementary Material (Figs. S1, S2 and S3).

\subsection{Reversibility of impacts from land use and permanent} impacts

In the above reasoning, it is assumed that after a certain regeneration time, the ecosystem quality of the reference situation could be re-established. Of course, an ecosystem that has been changed by human activities or by natural forces will never be exactly the same. Ecosystem quality is a result of the interaction between life (ecosystems) with the abiotic environment, and life is, in the strict sense of the word, not reversible. However, the forces of nature are able to veil the traces of most human activities if these forces are free to act during decades, centuries or millennia: abandoned human settlements or structures are sooner or later wiped out and reconverted to a quasi-natural land cover which depends on the biogeographical conditions of the location.

In the context of land use, it is proposed to consider impacts generally as reversible in the broad sense of reversibility. This means that abandoned land spontaneously develops towards a site-dependent potential natural vegetation (PNV) if the absence of human action continues during a sufficient length of time (regeneration time, also called relaxation time). At the end, an abandoned area can be considered as roughly equivalent, although not identical, to its pre-impact state. However, there are situations where the regeneration time, according to current knowledge, will exceed the modelling horizons of usual LCA studies, or even will exceed any finite number of years: a high salinity area in very dry climate could be barren for an indefinite time period. Such impacts are called permanent impacts. Permanent impacts can be expressed by multiplying the difference $\Delta Q$ between the initial reference $\left(Q_{r e f}\right)$ and a new established steady state $\left(Q_{\text {ref } 2}\right)$ by the area of transformation and, alternatively, a certain modelling time (see equations in Fig. 2). Permanent impacts could also be quantified without choosing an (arbitrary) time horizon. However, it is recommended to multiply with a certain modelling time to get a standard unit of $\Delta Q \times$ time $\times$ area for all land use impacts, which allows to easily aggregate permanent, transformation and occupation impacts in the same units.

Nevertheless, such a pragmatic aggregation may have several issues regarding interpretation and effect on results. On the one hand, permanent impacts represent diminishing options for future development of a piece of land. On the
Fig. 2 Calculation of permanent impacts caused by land use change. For simplicity again, the area $A$ of occupation or transformation, which would embrace the third dimension, is not shown in the graph, but in the equations




other hand, occupation and transformation impacts rather describe actual, temporary impacts occurring during occupation/regeneration phase. For this reason, it can be argued that aggregation of temporary and permanent impacts is equivalent to aggregation of different impact categories. This implies weighting them against each other, but the value judgement, expressed by the time horizon over which permanent impacts are considered, should be made explicit as a value choice. As an overall consensus has not been reached among this workgroup, it is highly recommended to perform sensitivity analyses and discuss the influence of the modelling choices on the conclusion of the study, i.e. aggregating or not permanent impacts into a single result and, in case of aggregation, the choice of timeframe.

Figure 2 illustrates how permanent, transformation and occupation impacts are calculated if full recovery of ecosystem quality is not possible within the modelling time. Initially (time $t_{1}=0$ ), land is transformed from a reference (e.g. tropical rain forest) to land use type LU1 (e.g. pasture), having a permanent (damaging) effect on ecosystem quality. After a regeneration period of $t_{3}-t_{2}$ years, a new steady state $Q_{\text {ref } 2}$ (e.g. old growth secondary forest) is reached. Transformation and occupation impacts of $L U 1$ as well as the subsequent LU2 (e.g. arable land) are then calculated based on $\Delta Q=Q_{\text {ref } 2}-Q_{L U 1 / L U 2}$ (see Eqs. I-IV in Fig. 2). The permanent impact can either be expressed by the $\Delta$ between $Q_{\text {ref }}$ and $Q_{\text {ref 2 }}$, represented by the curled bracket, or by the area $\mathrm{Ib}$ (see Fig. 2), representing the maintenance of an ecosystem quality below the initial reference $\left(Q_{\text {ref }}\right)$ for the modelling period defined (e.g. $t_{M}=500$ years). Permanent (and transformation) impacts would then be allocated to the products obtained from land during the first 20 years (see Section 3.2.4).

Based on this approach, impacts occurring after the modelling period (i.e. $Q_{\text {ref }}-Q_{\text {ref } 2}$ after year 500 in Fig. 2) are not accounted for. However, it is important to note that such a modelling decision is similar to the modelling choices adopted by the modelling period of global warming potential (see Section 3.3.1).

\subsection{Impact proportional to relative or absolute quality change?}

As mentioned before, the magnitude of permanent, transformation and occupation impacts is dependent on the difference in ecosystem quality $(\Delta Q)$ between a reference and a land use situation. $\Delta Q$ can be calculated based on absolute or relative differences, and which of both is preferable is subject of an ongoing debate.

For the land use impact on carbon storage, the absolute $\Delta Q$ is clearly preferable as the goal is to identify the amount (in tonnes) of sequestered $\mathrm{C}$ released into the air in form of $\mathrm{CO}_{2}$ due to the land transformation. This contributes to impact on climate change (and consequently on human health and non-human life), which is controlled by absolute flows in $\mathrm{C}$ or $\mathrm{CO}_{2}$ tonnes. Measuring $\Delta Q$ in relative terms would not make sense, as releasing $50 \%$ of the carbon stored in a carbonrich vegetation has clearly not the same impact as releasing $50 \%$ of the carbon stored in a carbon-poor vegetation. The same holds true for other ecosystem services, as mostly the absolute amount of service provided is of importance.

Less clear is the case of the biodiversity impact. If a factory building is erected on species-poor land (e.g. with 10 species), or alternatively on a species-rich land (e.g. with 100 species), the relative biodiversity $\Delta Q$ would be $100 \%$ for both alternatives, whilst the impact on species-rich land is ten times higher than on the species-poor land in absolute terms. Selecting relative or absolute impacts is finally based on a value choice: choosing relative impacts gives equal weight to ecosystems, whereas choosing absolute impacts gives equal weight to species.

In conclusion, it is recommended to calculate absolute impacts for ecological functions and ecosystem services on a global scale. When compared to relative impacts, such results are easier to interpret and allow coordination between different impact pathways. However, both absolute and relative impacts are deemed appropriate and are a matter of value choices for biodiversity. To allow better comparison of results across impact pathways, assessing biodiversity in absolute terms would be strongly advised. However, the challenge remains as current heterogeneity of available empirical data on a global level do not necessarily allow for an absolute impact assessment.

\section{Results: guideline of a global land use impact assessment method}

Building on the recommendations by (Milà i Canals et al. Milà i Canals 2007a), this paper provides guiding principles for the development of impact assessment methods for biodiversity and ecosystem services. The guideline suggests options with respect to the creation of a spatial model, the inventory data collection as well as the land use impact calculation (Fig. 3). Based on the work of Saad et al. (2011), Fig. 3 highlights a series of key elements to be accounted for when developing a land use impact assessment method and thus proposing new characterisation factors (CFs).

In an effort to provide a transparent and comprehensive approach for the creation of the model, it is suggested to explicitly state and define: which impact pathways with respect to biodiversity and ecosystem services are modelled (1a), which land use/cover typology (1b) as well as the biogeographical differentiation level (1c) are used for the development of CFs and, in addition to the reference situation (1d), whether relative or absolute quality changes (1e) are 
Fig. 3 Elements of the UNEPSETAC guideline to build a land use impact assessment for biodiversity and ecosystem services (adapted from Saad et al. 2011)

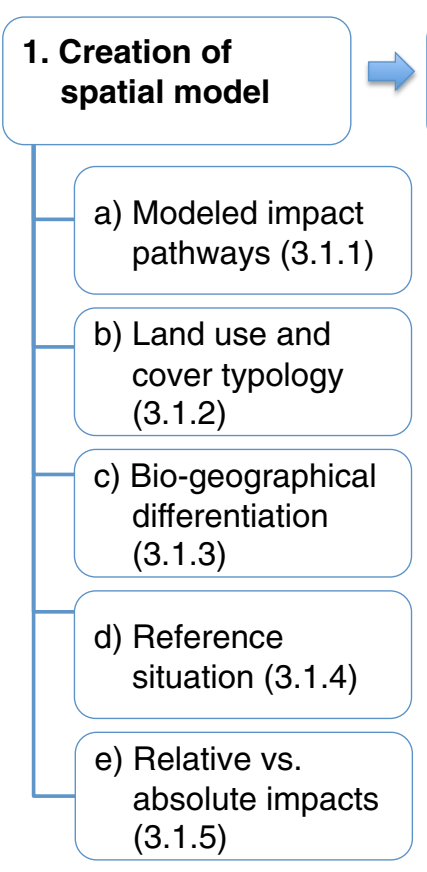

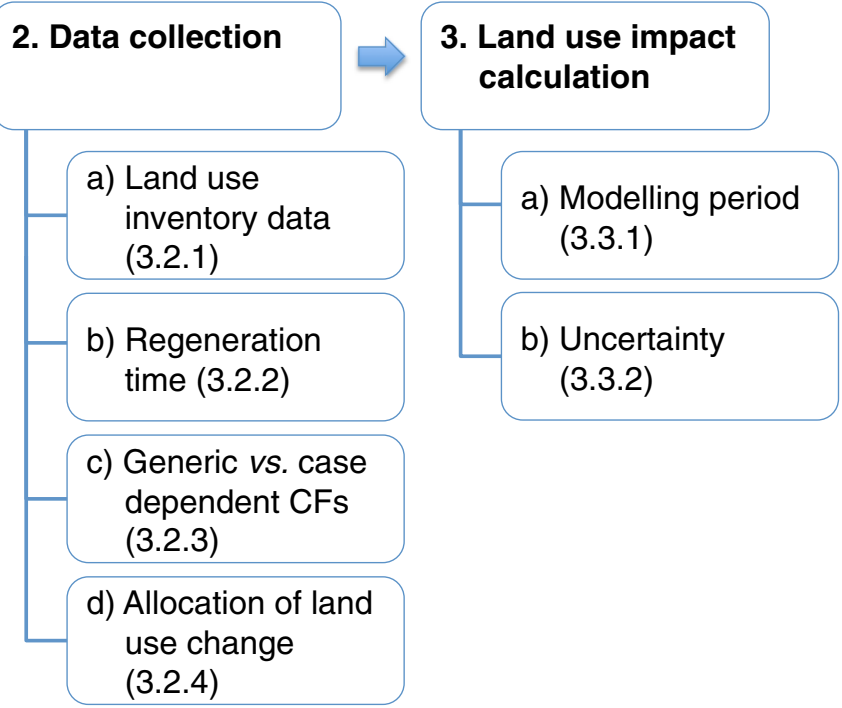

used for the calculation of land use impacts. In practice, when applying CFs in an LCA study, the data collection should be transparent with respect to the data input required from the land use inventory ( $2 \mathrm{a})$ and the regeneration time defined. It is also recommended to indicate how generic CFs can be used for the background system as well as how spatial-based CFs can be calculated for the foreground system if needed in a specific LCA study (2c) and how land use change is allocated to functional units $(2 \mathrm{~d})$. With regards to the land use impact calculation, it becomes necessary to justify the modelling period for which the impacts of land transformation and occupation are calculated ( $3 a$ ) and finally how the uncertainty of the impact assessment is assessed (3b).

The following sections provide guidance on how to apply such principles, and examples of their application are proposed in the methodological papers of this special issue.

\subsection{Creation of spatial model}

\subsubsection{Modelled impact pathways}

Land use intentionally and unintentionally influences the biodiversity as well as the structure and functions of ecosystems, causing damages to the areas of protection as defined in Jolliet et al. (2004). Figure 4 shows the cause-effect chain linking the land use with impacts on the four areas of protection. In order to enhance global relevancy of LCIA research, it is essential to link LCA activities to other ongoing research on ecological impact assessment. For this reason, a structure of the LCIA, which is in accordance with the globally acknowledged typology of ecosystem services of the Millennium Ecosystem Assessment (MA 2005) is proposed. Therefore, two main impact pathways are distinguished: biodiversity damage potential and ecosystem services damage potential (Table 1). For each of the impact pathways, Table S2 (Electronic Supplementary Material) holds Excel files with the generic CFs. The calculation of those CFs is described in detail for biodiversity (de Baan et al. 2013; Souza et al. 2013) and for the ecosystem services (Müller-Wenk and Brandão 2010; Brandão and Milà i Canals 2013; Saad et al. 2013).

The biodiversity damage potential includes the protection of global species diversity and also the functional diversity of species in ecosystems. The ecosystem services damage potential is structured according to the classification suggested by the Millennium Ecosystem Assessment into services provided by ecosystems. The focus lays on the development of generic characterization factors for the following impacts linked to land use: the impact on the potential of the ecosystem to produce biomass (Biotic Production Potential); the impact on climate by influencing the carbon sequestration in the top soil and land cover (Climate Regulation Potential); the impacts on water quantity and quality (freshwater regulation potential and water purification potential); and the impacts on soil quantity and quality (erosion regulation potential). This is an initial list of recommended impact categories linked to land use for which characterization models were available or under development. Nonetheless, the framework remains open to include additional midpoint oriented impact indicators if needed, such as the microbial activity indicating soil fertility. This would only be necessary if the new indicators show different results than those already provided by the current suggested list. In a comprehensive approach, new characterization methods for land use LCIA should specify the impact pathways 


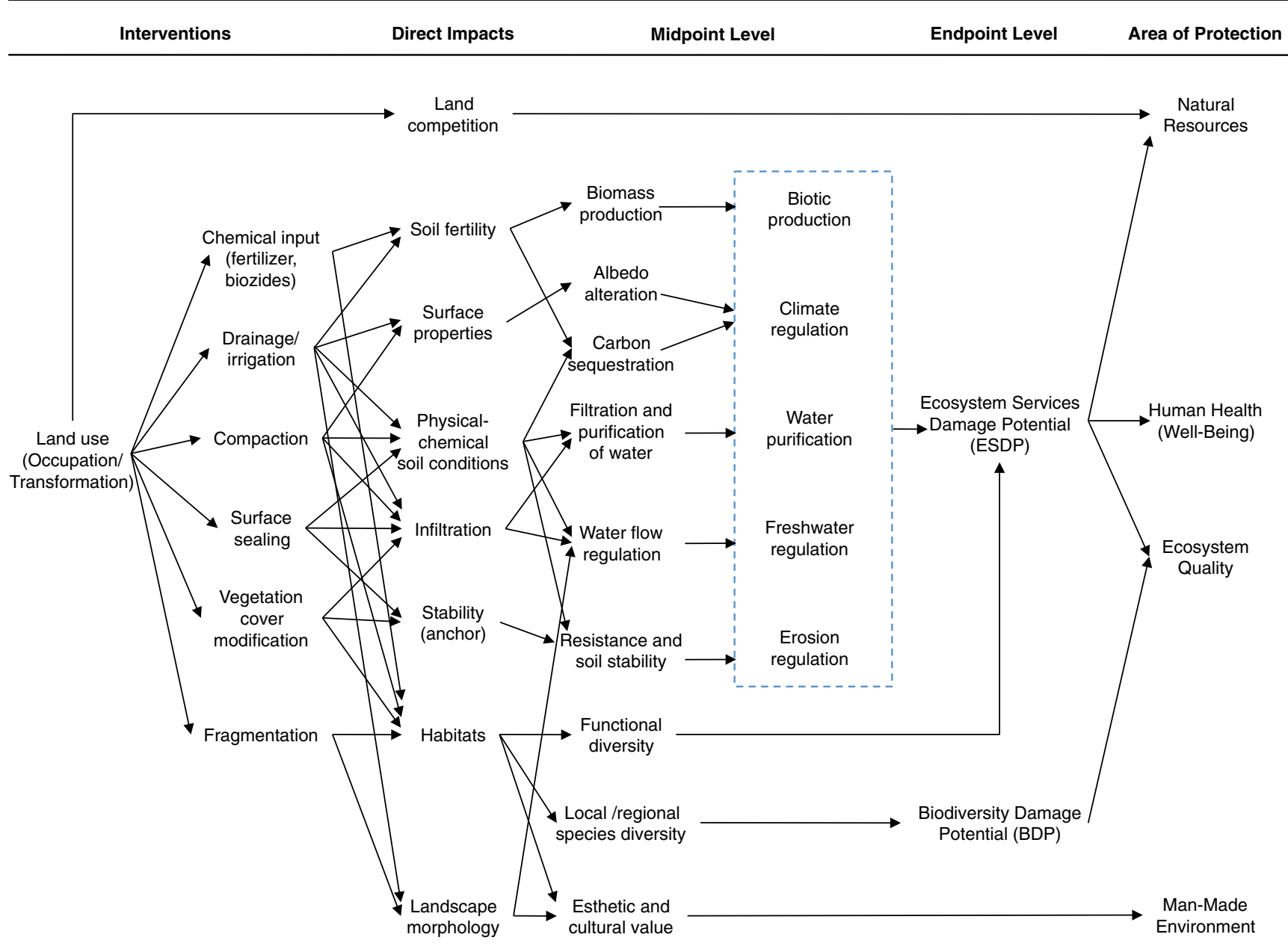

Fig. 4 Cause-effect chain for land use impacts on biodiversity and ecosystem services (adapted from Lindeijer et al. 2002). For more explanation on the specific impact pathways, see Table 1 and the papers in this special issue

modelled within the framework. Future studies exploring the links between different ecosystem services, and between ecosystem services and biodiversity are strongly recommended.

\subsubsection{Land use and cover typology}

For a globally applicable land use LCIA, it is desirable that land cover classes and land use types related to them are determined in a consistent and generally accepted way for all continents, and that available land cover data are recorded according to such a classification. A hierarchical approach of land use classes in LCA is given in this special issue (Koellner et al. 2013). It consists of four levels of detail, ranging from very general global land cover classes, to more refined categories and very specific categories indicating land use intensities.

New LCIA methods should be able to differentiate between all major land use types generally accounted for in LCA and specify the level of differentiation achieved. Thus, the classification suggested by Koellner et al. (2013) can be used as a starting point. It is foreseeable that the same level is not achieved for all major land use types (e.g. a method may differentiate agricultural land up to level 3, while other land uses such as forestry or artificial areas are only specified at level 1).

\subsubsection{Biogeographical differentiation in land use impact assessment}

Biogeographical differentiation in land use LCIA is a major aspect to be considered since the same type of land use may trigger different impacts at different locations of the globe (Jolliet et al. 2004). Koellner et al. (2013) in this special issue suggest a hierarchical regionalisation on a global scale based on the classification system of biomes and ecoregions (Olson et al. 2001). Similarly to the case of land use typology, new LCIA methods for land use impacts should specify the level of biogeographical differentiation achieved.

\subsubsection{Reference situation}

As explained in Section 2.1 land use impacts as assessed in LCA are proportional to the difference in quality between 


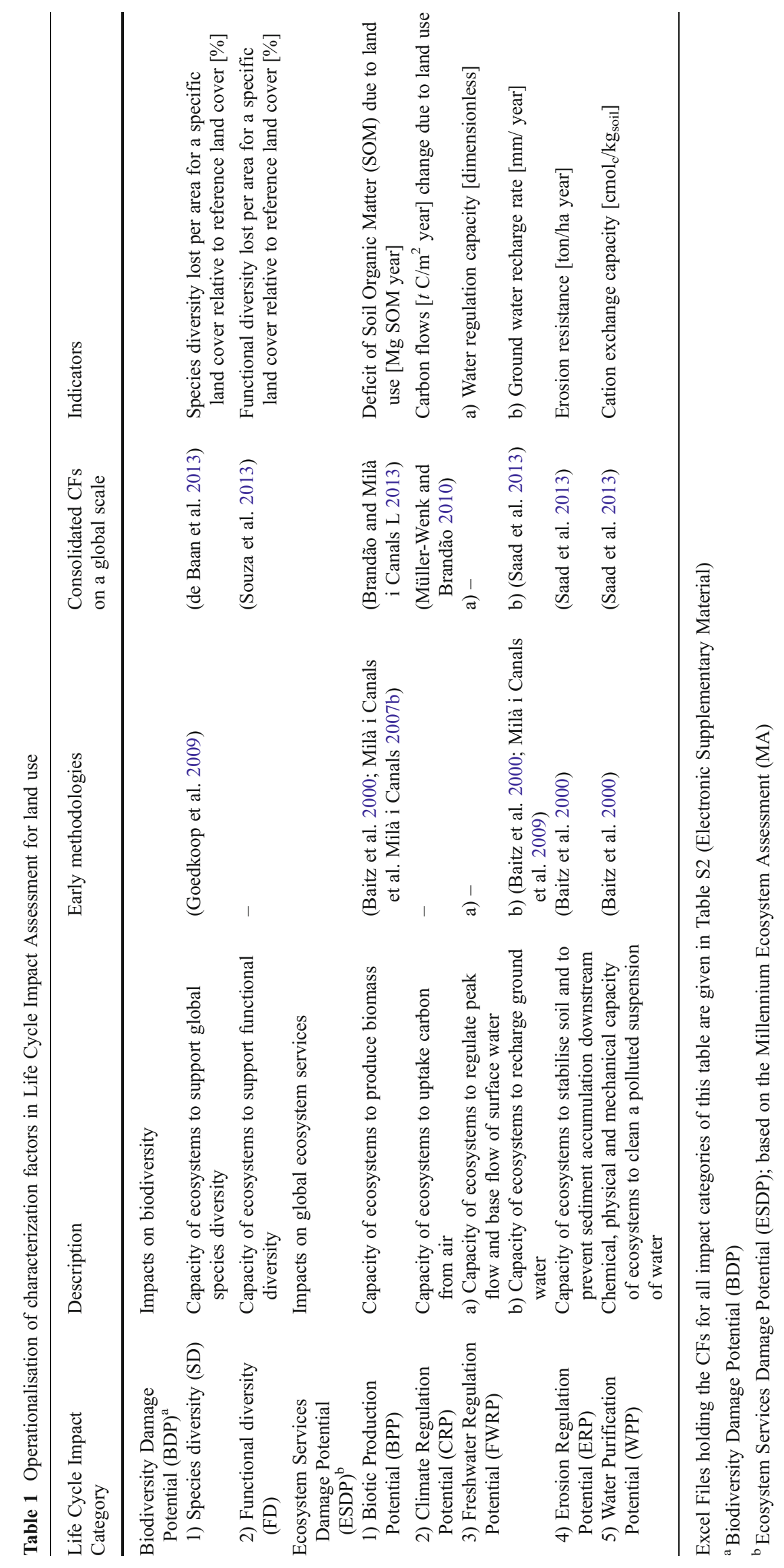


the studied system and a reference situation. Three main options are proposed to describe the reference:

- Option 1 is the concept of PNV, "which describes the expected state of mature vegetation in the absence of human intervention." (Chiarucci et al. 2010).

- Option 2 is to take as the reference states the (quasi-) natural land cover in each biome/ecoregion, i.e. the natural mix of forests, wetlands, shrubland, grassland, bare area, snow and ice, lakes and rivers.

- Option 3 is the current mix of land uses as reference as proposed for Europe (Koellner and Scholz 2008).

Options 1 and 2 are probably close enough to each other for the purposes of LCA. On the one hand, global data on the properties of potential "natural" land for many biogeographical regions are available in more or less satisfactory quality, so that it is globally practicable to assess anthropogenic land use impacts against the potential "natural" land cover defined as a reference. On the other hand, the current mix of land uses is a moving yardstick and would not be very practical in terms of definition.

In conclusion, and in accordance to Milà i Canals et al. (2007a), it is recommended to use the (quasi-)natural land cover predominant in global biomes and ecoregions as a reference when assessing land use impact on a global scale. Nevertheless, defining a reference situation is an area for further exploration recognised as a value choice, as using options 1 or 2 vs. option 3 supports different types of decisions (see Milà i Canals L et al. 2013).

\subsubsection{Absolute or relative land use impacts}

For each land use LCIA, it should be made explicit if land use impacts are assessed as absolute or relative changes to a reference situation. However, based on the above reasoning (see Section 2.3), it is generally recommended to calculate absolute land use impacts.

\subsection{Data collection}

\subsubsection{Land use inventory data}

Land use inventory flow for land occupation and land transformation are measured in $\mathrm{m}^{2}$ years and in $\mathrm{m}^{2}$, respectively. Although the level of differentiation (land use typology and spatial scale) may vary between methods (see Table S1 in the Electronic Supplementary Material), both the land use type and biogeographical information should be registered based on the proposal on global land use inventories presented in this special issue (Koellner et al. 2013). The level of detail in the land use type classification and the ecosystem type refinement depends on the scope of the LCA study and on whether it occurs in the foreground or the background system; see e.g. the discussions in the case study presented in this special issue (Milà i Canals L et al. 2013). If land use types are completely unknown in the product system, assuming a mix of intensive land use composed of forest, pasture/meadow, (non-) irrigated arable, permanent crops and artificial areas based on the proportions in the Global Land Cover 2000 is recommended. To assume intensive land use should stimulate the search for specific information for unknown land use types.

\subsubsection{Regeneration time}

Assuming that land use impacts are reversible (reversibility in the broad sense), the key question is, how many years after abandonment are needed until man-made traces in vegetation and soil have essentially disappeared? The length of this regeneration time, essential for the calculation of transformation impacts (see Section 2.1), depends mainly on the following factors:

- The impact pathway: on a given plot, it may take more time to regenerate biodiversity than to regenerate the biotic production capacity

- The type of land transformation: it takes more time to regenerate a forest, if the transformation resulted in sealed urban land, in comparison to a transformation resulting in cropland

- The biogeographical conditions of the location: regeneration is generally faster in warm and humid climate than in cold or dry climate.

As a consequence, each of the impact pathways requires a set of regeneration times per type of transformation and per climatic region. However, as current land use intensity in many parts of the world is a historically new phenomenon, knowledge on regeneration times of ecosystems within intensely used landscapes is limited or hardly available.

For impact pathways that are mostly dominated by soil carbon, it is recommended to use the regeneration time values for carbon storage in vegetation and soil provided by Müller-Wenk and Brandão (2010) for the impact pathway carbon sequestration potential (CSP). However, one should acknowledge that regeneration times for other impact categories derived from CSP data in this way are highly uncertain and strongly influence the transformation results.

With respect to the biodiversity damage potential, Koellner and Scholz (2007) give rough estimates for regeneration times based on Bastian and Schreiber (1999). Those data indicate that mature peat bogs and old growth forests take up to 1,000 years for complete regeneration in the temperate zone. This regeneration of forests might be speeded up in tropical climate to 100 300 years if species richness is taken as an indicator, 
but roughly the same when endemism is considered as the benchmark (Liebsch et al. 2008).

Generally, regeneration time increases towards poles and with altitude. It also depends on the impact type as well as the ecosystem function or taxonomic group considered (Jones and Schmitz 2009). To take this into consideration, data based on altitude and latitude made for regeneration of biomass after land has been cleared, assuming no soil degradation are provided in (van Dobben in Lindeijer et al. 1998, Annex 1.23). These numbers can be used as proxies to estimate regeneration of cleared land in different biomes or ecoregions, by calculating an area weighted average per region (depending on the share of total land within different altitudinal and latitudinal classes). However, further assumptions are needed to estimate regeneration time of different land use types within one biome or ecoregion. For example, a constant regeneration rate $r$ (decrease of $\Delta Q$ per time) could be assumed across land use types, which can be calculated as:

$r=\Delta Q / t_{\text {reg }}=\left(Q_{\text {ref }}-Q_{\text {cleared }}\right) / t_{\text {reg, }, \text { cleared }}$

where $Q_{r e f}$ is the ecosystem quality of the reference, $Q_{\text {cleared }}$ that of a land from which vegetation cover was removed completely but no soil degradation took place, and $t_{\text {reg, cleared }}$ the time needed to regenerate an ecosystem after it has been cleared. However, such assumptions clearly do not reflect reality and should be used with caution. Since results of overall impact calculation for land transformation are very sensitive to regeneration time (see Schmidt 2008) and this factor is highly uncertain, we recommend providing uncertainty estimates by LCIA developers and using sensitivity analysis when applying CFs (e.g. using low and high estimates of regeneration times).

\subsubsection{Generic characterization factors versus case dependent calculation of impacts}

The use of generic characterization factors in LCA is a simplification in order to allow the calculation of land use impacts for the background system. As land use is often globally distributed, but the impacts on biodiversity and ecosystem services are clearly depending on the type and location of the land use, we recommend using differentiated CFs and link them consistently to differentiated land use inventories as proposed in this special issue. However, for the foreground system specific, CFs can be calculated and should be applied in LCA as shown by the LANCA tool for ecological functions (Beck et al. 2010) or by Geyer et al. (2010a, b) for biodiversity. This should enhance the validity of the impact assessment and should also reduce uncertainties.

\subsubsection{Allocation of land transformation impacts}

Impacts from land transformation have to be allocated to output (functional units) arising from the new land use. This allocation or amortisation of land transformation belongs to the inventory, whereas calculating the magnitude of the land transformation impacts (integration of $\Delta Q$ between studied land use and reference over time, per area of land transformation) lies in the LCIA phase.

One option is to take a fixed amortisation period for all land use types. Twenty years would be consistent with IPCC suggestion for soil organic carbon emissions (IPCC 1996; Flynn et al. 2012). Allocating the transformation impact on the production output of 20 years represents a good compromise between allocating them all to the first year (and thus quickly loosing sight of the effects of LUC) and using a long allocation period (which could lead to a quasi-elimination of transformation impacts in the LCA results). An alternative is to assume different amortisation periods depending on the land use type. This was proposed in Ecoinvent $\mathrm{v} 2.0$ (Frischknecht and Jungbluth 2007, Table 5.5) based on default use periods. Alternatively, a linear depreciation along the regeneration pathway could be applied. For example, Fig. 1 shows that transformation impact $T I_{\text {ref }}$ $>L U 2$ would be 0 when $t^{\prime}$ is reached. After that, the impact is $100 \%$ related to the occupation. This means the regeneration time for a specific land transformation equals the appreciation period.

However, the actual number of years is arbitrary in any case. In the absence of a clear, scientifically robust alternative, we suggest using 20 years as an allocation period, as this is in line with standards and regulations for land use-derived greenhouse gas emissions allocation (IPCC 1996; BSI 2008) but also recommend sensitivity analysis.

\subsection{Land use impacts calculation}

\subsubsection{Modelling period for land use impacts}

The basic principles for the calculation of land use impacts from occupation and transformation are shown above (Section 2.1). Occupation impacts are modelled over the occupation time and thus no consideration of modelling period is necessary. But for transformation impacts, this calculation requires defining the modelling period: "the time lag between the land use intervention and the impact may be large; thus land use impacts should be calculated over a reasonable time period after the actual land use finishes..." (Milà i Canals et al. Milà i Canals 2007a). The modelling period is the time (years) over which the impacts caused by land use are integrated (i.e. difference between current impacts and a reference situation). 
Considering an arbitrary and finite modelling period is a practical solution, which deviates from the recommendations in Milà i Canals et al. (2007a), who suggest that "the impacts on ecosystem quality should be assessed at least until a new steady state in ecosystem quality is reached by natural or human-induced relaxation" (regeneration); such modelling would introduce inconsistencies with different land transformations, and would be hardly feasible in background systems (e.g. for LCI databases). The modelling period only has an effect on results when full recovery to reference situation is not achieved within this period (see Fig. 2).

Taking a modelling period out of the three $(20,100$ and 500 years) applied by IPCC for $\mathrm{CO}_{2}$ equivalents is a reasonable starting point. The modelling period should be chosen long enough to fully include the main transformation impacts measured by regeneration time. They can be estimated on the basis of observed re-vegetation on old quarries, past agricultural sites and closed railway tracks with known date of abandonment. As shown above, natural regeneration in temperate or boreal forest biomes takes clearly more time than 100 years. That is why a modelling period of 500 years was used by Müller-Wenk and Brandão (2010). In this guideline, a 500 years modelling period in land use LCIA is proposed as it is adequate in view of the long-term natural processes involved.

\subsubsection{Uncertainty}

Uncertainty is inherent in all steps of the calculation of global ecological impacts of land use. Firstly, using statistical measures quantifying the statistical uncertainty of CFs is highly recommended. The first and best approach is to compare differences in the means of the CFs with statistical methods like ANOVA. The standard error (calculated as standard deviation divided by the root of sample size $n$ ) allows users to identify CFs with a high standard deviation in relation to the sample size, which are not appropriate for the use in LCA studies (Koellner and Scholz 2008). In cases where assumptions of normal distributions cannot be met and parametric statistics can therefore not be applied, nonparametric statistics based on differences in median and percentiles should be used. Such information can be used in Monte Carlo simulations or sensitivity analysis to assess the overall uncertainty of the impact assessment. This helps users to interpret the current state of knowledge on land use impacts assessment (e.g. which impact pathways are most uncertain and which parameters are uncertain and need to be better investigated) and should also allow identifying research priorities. Second, in order to assess the data quality, we recommend to develop a pedigree matrix similar to what was presented in Ecoinvent 2.0 (Frischknecht and Jungbluth 2007, p. 45) and Ecoinvent 3.0 (Weidema et al. 2011, p. 83) to assess the reliability of the data and the models behind specific characterisation factors, the completeness of the impact pathway as well as temporal/geographical representativeness.

\section{Discussion: problems of global impact assessment}

\subsection{Simplifications and assumptions}

Assessing the ecological impacts of land use on a global scale is a complex matter. Several simplifications, assumptions and decision choices are linked with this approach of the calculation of generic CFs for land use impacts. The main ones related to land transformation and occupation are the following:

- Discrete land cover types based on environmental factors like vegetation cover are the basis of assessing ecological impacts; however, estimates of ecosystem service changes may be inaccurate because species distributions and their functional properties can vary considerably within one land cover type (Eigenbrod et al. 2010). Replacing land cover maps with continuous environmental information including species functional traits as input into ES models is likely to increase the model validity (see Lavorel et al. 2010).

- Ecosystem quality $Q$ remains constant over occupation time. This is not necessarily the case as during occupation, $Q$ can change (Milà i Canals 2007a).

- Time and area of occupation can be fully substituted to achieve a constant output (e.g. one ton of crop). This might be true for the inventory, but in terms of ecological impact, it can matter either to use a small area for a long time or a large area for a short time (Koellner and Scholz 2007), or one single large plot versus many smaller ones.

- Transformation time is zero. This assumption is made, because in most LCA applications, transformations imply worsening ecosystem quality, which in many cases requires not much time (e.g. deforestation and building of infrastructure). However, in cases of transformations improving the ecosystem quality (e.g. from agriculture to forest), this might not be appropriate.

- Ecological impact is linearly increasing with the intervention of occupation and transformation. However, biodiversity and ecosystem services might respond nonlinearly to land use pressure (Carpenter et al. 2009). In LCA, a marginal approach is taken to account for this with the assumption that the "concentration" of land use is not considerably changed in the background system given the intervention at stake. However, the question is at which threshold does an intervention influence the start of background system and non-linear system response. 
- Biodiversity and the multiple ecosystem services are independent. However, research shows clearly there is an interaction between them (Balvanera et al. 2006; Bennett et al. 2009; Raudsepp-Hearne et al. 2010). A first step towards addressing impacts of biodiversity changes on ecosystem services is the assessment of functional diversity in LCA. It is also important to assess the relationship between impact results of different ecosystem services (see e.g. Milà i Canals L et al. 2013).

- Multiple drivers of ecosystem services and biodiversity loss do not interact. In most product systems, multiple environmental impacts occur, such as climate change, pollution, land use and the combined effects can lead to non-additive reactions of ecosystem services and biodiversity.

The following assumptions are made with respect to ecosystem regeneration, which is a major factor to assess transformation impacts:

- Regeneration is linear and independent from the land use history, i.e. only the last land use before abandonment is important and time of occupation is not relevant. This is certainly not appropriate for many cases as land use history determines the potential of ecosystems to recover. Ecosystems might also react non-linearly in their regeneration depending on their resilience (Folke et al. 2004).

- Configuration of a landscape is not influencing regeneration time and the degree of regeneration (e.g. permanent impacts). Factors like the proximity to primary habitat, connectivity of landscape and availability of remaining primary habitat are not considered for biodiversity impacts. This could be addressed by a statistical approach as shown for Switzerland (Koellner 2003, p. 97-125, Koellner et al. 2004).

- No active restoration was assumed. Until now, we assumed that ecosystems regenerate naturally without human influence. However, in some cases, technical means might contribute to ecosystem restoration (as for example applied in the restoration of mining sites) and can shorten the regeneration time. It is uncertain to which extent this is possible for ecosystem services and for biodiversity on larger scales, and particularly for land use in the background system.

\subsection{Separation of land use and water use}

The impact category land use is often closely linked to the water use category. This is typically the case for irrigated agriculture, where the irrigation is part of the land use practice, but at the same time linked to the water used. Land use changes can also induce indirect changes in the water cycle. For instance, deforestation or surface sealing can change water infiltration, evapotranspiration and runoff, leading to changes in groundwater aquifer recharge and thereby influence freshwater availability in a specific region. This eventually may cause adverse impacts on downstream ecosystems and their biodiversity (Pfister et al. 2009), which may have significant contributions to the overall system's water-related impacts (Milà i Canals et al. 2010). More discussion on overlap and complementarities between the two impact categories is given in Koellner et al. (2011a).

\subsection{Support to decision-making}

It is acknowledged that the value of the LCA results for decision-making depends heavily on the appropriateness of the LCI and LCIA approaches taken. In this sense, it is important to highlight that the choice of reference situation is a key element for the decision maker and should be fully appreciated for a proper interpretation of the results. The approach suggested in this guidance is to consider a biomedependent (quasi-)natural land cover as a reference. However, policy makers wanting to protect the current environmental quality may not be interested in knowing how far we are from an idealistic, quasi-natural situation. For this purpose, approaches relying on realistic scenarios of ecosystem development on a landscape scale should be developed. In addition, the spatial disaggregation to biome level is probably relevant as a first step of spatial differentiation for global life cycles as shown in some case studies (see Milà i Canals L et al. 2013); however, if the decision maker wanted to support e.g. land use policy in a sub-biome level (e.g. in a country), then the LCI information (and LCIA CF) provided would need to be at a further level of detail. This also requires to clearly identify complementary methods at the landscape scale such as environmental impact assessment and regional ecosystem service models (e.g. Nelson et al. 2009).

\section{Conclusion and recommendations}

The principles and recommendations presented here are applied in the other papers of this special issue for the development of CFs for land use impacts on biodiversity and ecosystem services on a global scale. Such recommendations go beyond the general framework presented by Milà i Canals et al. (2007a) and explore further specific aspects such as allocation of transformation impacts over 20 years; pragmatic consideration of irreversible impacts with finite modelling period of 500 years; classification of impact pathways aligned with the Millennium Ecosystem Assessment (2005); discussion on the validity of inherent assumptions in land use impact modelling (Section 4), consistent classification of different land use typologies and levels of 
biogeographical differentiation (Koellner et al. 2013) that goes beyond the "archetypical land uses" suggested in Milà i Canals et al. (2007a). Table S1 (Electronic Supplementary Material) summarises the impact pathways covered in the different papers and how the guideline presented in this paper has been followed in each one of them.

The presented CFs provided by the other papers of this special issue are developed for the global assessment of direct land use impacts in the background system. For a more elaborated assessment of land use impacts in the foreground system, regional models should be further developed and applied for biodiversity (Geyer et al. 2010a; Geyer et al. 2010b) and ecosystem services (Beck et al. 2010; Bare 2011). Indirect land use in a consequential approach is also not yet sufficiently considered in LCA, and even though it is part of the inventory, it may have important consequences in the impact assessment and needs further research. Brandão (2011) offers some key insights on the importance of indirect land use on the impact assessment results.

Weighting of ecosystem services midpoints and their independence are not yet addressed. As they link to the human well-being according to the Millennium Ecosystem Assessment, such weighting can be based on the societal demand. For example, the relative importance can be expressed in their economic value (Costanza et al. 1997). Before such weighting is proposed, it would be worth to thoroughly explore whether the plethora of ecosystem services quantified in this special issue provide differentiated results, or whether they are all so inter-linked that assessing one of them would be enough. However, weightings of ecosystem services midpoints as well as many decisions done along the development of LCIA are clearly a matter of value choices. Further developments should make them consistently transparent for archetypical cultural perspectives (Hofstetter 1998; De Schryver et al. 2010).

\footnotetext{
Acknowledgments The authors wish to thank the UNEP-SETAC Life Cycle Initiative for financial support of this work under the project Operational Characterization Factors for Land Use Impacts on Biodiversity and Ecosystem Services in the Life Cycle Impact Assessment - Compatible with the Framework of the UNEP-SETAC Life Cycle Initiative (LULCIA). In addition, we are grateful for the comments of two anonymous reviewers and for those of Thomas E. McKone and Till Bachmann. The designations employed and the presentation of the material in this publication do not imply the expression of any opinion whatsoever on the part of the United Nations Environment Programme concerning the legal status of any country, territory, city or area or of its authorities, or concerning delimitation of its frontiers or boundaries. Moreover, the views expressed do not necessarily represent the decision or the stated policy of the United Nations Environment Programme or any participants such as members of the International Life Cycle Board, nor does citing of trade names or commercial processes constitute endorsement. Information contained herein does not necessarily reflect the policy or views of the Society of Environmental Toxicology and Chemistry (SETAC). Mention of commercial or non-commercial products and services does not imply endorsement or affiliation by SETAC.
}

Open Access This article is distributed under the terms of the Creative Commons Attribution License which permits any use, distribution, and reproduction in any medium, provided the original author(s) and the source are credited.

\section{References}

Antón A, Castells F, Montero J (2007) Land use indicators in life cycle assessment Case study: the environmental impact of Mediterranean greenhouses. J Clean Prod 15:432-438

Baitz M, Kreißig J, Wolf M (2000) Methode zur Integration der Naturraum-Inanspruchnahme in Ökobilanzen. Forstwirtschaftliches Centralblatt 119:128-149

Balvanera P, Pfisterer AB, Buchmann N, He J-S, Nakashizuka T, Raffaelli D, Schmid B (2006) Quantifying the evidence for biodiversity effects on ecosystem functioning and services. Ecol Lett 9:1146-1156

Bare J (2011) Recommendation for land use impact assessment: first steps into framework, theory, and implementation. Clean Techn Environ Policy 13:7-18

Bastian O, Schreiber K-F (eds) (1999) Analyse und ökologische Bewertung der Landschaft. Spektrum Akademischer Verlag, Heidelberg, Berlin

Beck T, Bos U, Wittstock B, Baitz M, Fischer M, Sedlbauer K (2010) LANCA-land use indicator value calculation in life cycle assessment. Fraunhofer, Stuttgart

Bennett E, Peterson G, Gordon L (2009) Understanding relationships among multiple ecosystem services. Ecol Lett 12:1394-1404

Brandão M (2011) Food, Feed, Fuel, Timber or Carbon Sink? Towards sustainable land-use systems - a consequential life cycle approach, Centre for Environmental Strategy, Faculty of Engineering and Physical Sciences. University of Surrey, Guildford, UK, PhD thesis

Brandão M, Milà i Canals L (2013) Global characterisation factors to assess land use impacts on biotic production. Int J Life Cycle Assess. doi:10.1007/s11367-012-0381-3

BSI (2008) PAS2050: Specification for the assessment of the life cycle greenhouse gas emissions of goods and services. British Standards Institution (BSI), London, UK

Carpenter SR, Mooney H, Agard J, Capistrano D, DeFries R, Díaz S, Dietz T, Duraiappah A, Oteng-Yeboah A, Pereira HM (2009) Science for managing ecosystem services: beyond the Millennium Ecosystem Assessment. PNAS 106:1305

Cederberg C, Mattsson B (2000) Life cycle assessment of milk production - a comparison of conventional and organic farming. J Clean Prod 8:49-60

Chiarucci A, Araújo MB, Decocq G, Beierkuhnlein C, FernándezPalacios JM (2010) The concept of potential natural vegetation: an epitaph? J Veg Sci 21:1172-1178

Costanza R et al (1997) The value of the world's ecosystem services and natural capital. Nature 387:253-260

Curran M, Ld B, Schryver AMD, Rv Z, Hellweg S, Koellner T, Sonnemann G, Huijbregts MAJ (2011) Toward meaningful end points of biodiversity in Life Cycle Assessment. Environ Sci Technol 45:70-79

de Baan L, Alkemade R, Koellner T (2013) Land use impacts on biodiversity in LCA: a global approach. Int J Life Cycle Assess. doi:10.1007/s11367-012-0412-0

de Groot RS (1992) Functions of Nature. Evaluation of nature in environmental planning, management and decision making. Wolters-Noordhoff, Amsterdam, The Netherlands

de Groot RS, Wilson MA, Boumans RMJ (2002) A typology for the classification, description and valuation of ecosystem functions, goods and services. Ecol Econ 41:393-408 
De Schryver AM, Goedkoop MJ, Leuven RSEW, Huijbregts MAJ (2010) Uncertainties in the application of the species area relationship for characterisation factors of land occupation in life cycle assessment. Int J Life Cycle Assess 15(7):682691

Eigenbrod F, Armsworth P, Anderson B, Heinemeyer A, Gillings S, Roy D, Thomas C, Gaston K (2010) The impact of proxy-based methods on mapping the distribution of ecosystem services. $\mathrm{J}$ Appl Ecol 47:377-385

Flynn D, Gogol-Prokurat M, Nogeire T, Molinari N, Richers BT, Lin B, Simpson N, Mayfield M, Declerck F (2009) Loss of functional diversity under land use intensification across multiple taxa. Ecol Lett 12:22-33

Flynn HC, Milà i Canals L, Keller E, King H, Sim S, Hastings A, Smith P (2012) Quantifying global greenhouse gas emissions from land-use change for crop production. Glob Change Biol 18 (5):1622-1635

Folke C, Carpenter S, Walker B, Scheffer M, Elmqvist T, Gunderson L, Holling CS (2004) Regime shifts, resilience, and biodiversity in ecosystem management. Annu Rev Ecol Evol S 35:557-581

Frischknecht R, Jungbluth N (eds) (2007) Ecoinvent: overview and methodology. Swiss Centre for Life Cycle Inventories, Dübendorf

Geyer R, Lindner JP, Stoms DM, Davis FW, Wittstock B (2010a) Coupling GIS and LCA for biodiversity assessments of land use: Part 2: Impact assessment. Int J Life Cycle Assess 15:692-703

Geyer R, Stoms D, Lindner J, Davis F, Wittstock B (2010b) Coupling GIS and LCA for biodiversity assessments of land use. Part 1: Inventory modeling. Int J Life Cycle Assess 15:454-467

Goedkoop M, Heijungs R, Huijbregts M, Schryver AD, Struijs J, van Zelm R (2009) ReCiPe 2008, A life cycle impact assessment method which comprises harmonised category indicators at the midpoint and the endpoint level. PRé Consultants, Amersfoort, Netherlands

Hofstetter P (1998) Perspectives in Life Cycle Impact Assessment. A structured approach to combine models of the technosphere, ecosphere and valuesphere. Kluwer, Boston, Dordrecht, London

IPCC (1996) Revised 1996 IPCC Guidelines for National Greenhouse Gas Inventories. In: Houghton JT, Meira Filho LG, Lim B, Treanton K, Mamaty I, Bonduki Y, Griggs DJ, Callender BA (eds) IPCC/OECD/IEA. Meteorological Office, UK

Jolliet O, Müller-Wenk R, Bare J, Brent A, Goedkoop M, Heijungs R, Itsubo N, Peña C, Pennington D, Potting J (2004) The LCIA midpoint-damage framework of the UNEP/SETAC life cycle initiative. Int J Life Cycle Assess 9:394-404

Jones HP, Schmitz OJ (2009) Rapid recovery of damaged ecosystems. PLoS One 4(e5653):1-6

Koellner T (2003) Land use in product life cycles and ecosystem quality, Bern

Koellner T, de Baan L, Beck T, Brandão M, Civit B, Goedkoop M, Margni M, Milà i Canals L, Müller-Wenk R, Weidema B, Wittstock B (2013) Principles for life cycle inventories of land use on a global scale. Int J Life Cycle Assess. doi:10.1007/ s11367-012-0392-0

Koellner T, Hersperger A, Wohlgemuth T (2004) Rarefaction method for assessing plant species diversity on a regional scale. Ecography 27:532-544

Koellner T, Pfister S, Koehler A (2011) Life cycle assessment and ecosystem services. In: Koellner T (ed) Ecosystem services and global trade of natural resources: ecology, economics and policies. Routledge, Oxon, UK, pp 151-171

Koellner T, Scholz RW (2007) Assessment of land use impacts on the natural environment. Part 1: An analytical framework for pure land occupation and land use change. Int J Life Cycle Assess $12: 16-23$

Koellner T, Scholz RW (2008) Assessment of land use impacts on the natural environment. Part 2: Generic characterization factors for local species diversity in Central Europe. Int J Life Cycle Assess $13: 32-48$

Lavorel S, Grigulis K, Lamarque P, Colace M-P, Garden D, Girel J, Pellet G, Douzet R (2010) Using plant functional traits to understand the landscape distribution of multiple ecosystem services. J Ecol 99:135-147

Liebsch D, Marques M, Goldenberg R (2008) How long does the Atlantic Rain Forest take to recover after a disturbance? Changes in species composition and ecological features during secondary succession. Biol Conserv 141:1717-1725

Lindeijer E, Müller-Wenk R, Steen B, Udo De Haes H et al (2002) Resources and land use. In: Jolliet O, Finnveden G, Goedkoop M, Hauschild M, Hertwich E (eds) Life-cycle impact assessment: striving towards best practice. SETAC Press, Pensacola, FL, USA

Lindeijer E, van Kampen M, Fraanje P, van Dobben H, Nabuurs GJ, Schouwenberg E, Prins D, Dankers N, Leopold MF (1998) Biodiversity and life support indicators for land use impacts in LCA. IVAM ER, IBN-DLO, Wageningen, Texel

MA (2005) Millennium ecosystem assessment. Ecosystems and human well-being: current state and trends. Island Press, Washington, DC

Maes W, Heuvelmans G, Muys B (2009) Assessment of land use impact on water-related ecosystem services capturing the integrated terrestrial-aquatic system. Environ Sci Technol 43:7324-7330

Michelsen O (2008) Assessment of land use impact on biodiversity - proposal of a new methodology exemplified with forestry operations in Norway. Int J Life Cycle Assess 13:22-31

Milà i Canals L (2003) Contributions to LCA methodology for agricultural systems. Site-dependency and soil degradation impact assessment. $\mathrm{PhD}$ thesis, available from [http://www.tdx.cesca.es/ TDX-1222103-154811/], Autonomous University of Barcelona, Spain

Milà i Canals L (2007) Editorial: Land use in LCA: a new subject area and call for papers. Int J Life Cycle Assess 12:1

Milà i Canals L, Bauer C, Depestele J, Dubreuil A, Freiermuth Knuchel R, Gaillard G, Michelsen O, Müller-Wenk R, Rydgren B (2007a) Key elements in a framework for land use impact assessment within LCA. Int J Life Cycle Assess 12:5-15

Milà i Canals L, Chapagain A, Orr S, Chenoweth J, Antón A, Clift R (2010) Assessing freshwater use impacts in LCA: Part II-case study for broccoli production in the UK and Spain. Int J Life Cycle Assess 16:598-607

Milà i Canals L, Chenoweth J, Chapagain A, Orr S, Anton A, Clift R (2009) Assessing freshwater use impacts in LCA: Part I-inventory modelling and characterisation factors for the main impact pathways. Int J Life Cycle Assess 14:28-42

Milà i Canals L, Rigarlsford G, Sim S (2013) Land use impact assessment of margarine. Int J Life Cycle Assess. doi:10.1007/s11367012-0380-4

Milà i Canals L, Romanya J, Cowell SJ (2007b) Method for assessing impacts on life support functions (LSF) related to the use of 'fertile land' in Life Cycle Assessment (LCA). J Clean Prod 15:1426-1440

Millennium Ecosystem Assessment (2005) Ecosystems and human well-being: synthesis. Island, Washington, DC

Müller-Wenk R, Brandão M (2010) Climatic impact of land use in LCA - carbon transfers between vegetationsoil and air. Int J Life Cycle Assess 15:172-182

Nelson E, Mendoza G, Regetz J, Polasky S, Tallis H, Cameron D, Chan K, Daily GC, Goldstein J, Kareiva PM, Lonsdorf E, Naidoo R, Ricketts TH, Shaw M (2009) Modeling multiple ecosystem services, biodiversity conservation, commodity production, and tradeoffs at landscape scales. Front Ecol Environ 7:4-11

Olson DM, Dinerstein E, Wikramanayake ED, Burgess ND, Powell GVN, Underwood EC, D'Amico JA, Itoua I, Strand HE, Morrison JC, Loucks CJ, Allnutt TF, Ricketts TH, Kura Y, Lamoreux JF, Wettengel WW, Hedao P, Kassem KR (2001) Terrestrial 
ecoregions of the worlds: a new map of life on Earth. BioScience 51:933-938

Pfister S, Koehler A, Hellweg S (2009) Assessing the environmental impacts of freshwater consumption in LCA. Environ Sci Technol 43:4098-4104

Raudsepp-Hearne C, Peterson G, Bennett E (2010) Ecosystem service bundles for analyzing tradeoffs in diverse landscapes. PNAS 107:5242-5247

Reinhard J, Zah R (2009) Global environmental consequences of increased biodiesel consumption in Switzerland: consequential life cycle assessment. J Clean Prod 17(suppl 1):S45-S56

Saad R, Koellner T, Margni M (2013) Land use impacts on freshwater regulation, erosion regulation and water purification: a spatial approach for a global scale. Int J Life Cycle Assess (this issue)

Saad R, Margni M, Koellner T, Wittstock B, Deschênes L (2011) Assessment of land use impacts on soil ecological functions: development of spatially differentiated characterization factors within a Canadian context. Int J Life Cycle Assess 16:198211

Schmidt J (2008) Development of LCIA characterisation factors for land use impacts on biodiversity. J Clean Prod 16:1929-1942

Souza DM, Flynn D, Rosenbaum RK, de Melo Lisboa H, Koellner T (2013) Land use impacts on biodiversity: proposal of characterization factors based on functional diversity. Int $\mathrm{J}$ Life Cycle Assess (this issue)
Udo de Haes H, Jolliet O, Finnveden G, Goedkoop M, Hauschild M, Hertwich E et al (2002) Life-cycle impact assessment: striving towards best practice. SETAC, Pensacola, FL, USA

Udo de Haes H, Jolliet O, Finnveden G, Hauschild M, Krewitt W, Müller-Wenk R (1999a) Best available practice regarding impact categories and category indicators in life cycle impact assessment. Background document for the second working group on Life Cycle Impact Assessment of SETAC-Europe (WIA-2) Part A. Int J Life Cycle Assess 4:66-74

Udo de Haes H, Jolliet O, Finnveden G, Hauschild M, Krewitt W, Müller-Wenk R (1999b) Best available practice regarding impact categories and category indicators in life cycle impact assessment. Background document for the second working group on Life Cycle Impact Assessment of SETAC-Europe (WIA-2) Part B. Int J Life Cycle Assess 4:167-174

Weidema B, Bauer C, Hischier R, Mutel C, Nemecek T, Vadenbo CO, Wernet G (2011) Overview and methodology. Data quality guideline for the ecoinvent database version 3. Ecoinvent Report 1(v3). The ecoinvent Centre, St. Gallen

Zhang Y, Baral A, Bakshi B (2010a) Accounting for ecosystem services in life cycle assessment, Part II: toward an ecologically based LCA. Environ Sci Technol 44:2624-2631

Zhang Y, Singh S, Bakshi B (2010b) Accounting for ecosystem services in life cycle assessment, Part I: a critical review. Environ Sci Technol 44:2232-2242 